\title{
Abstract \#283381
}

\section{MULTISPECTRAL VNIR OBSERVATIONS BY THE OPPORTUNITY ROVER PANCAM OF MULTIPLE EPISODES OF AQUEOUS ALTERATION IN MARATHON VALLEY, ENDEAVOUR CRATER, MARS}

FARRAND, William H., Space Science Institute, 4750 Walnut Street, \#205, Boulder, CO 80301, BELL III, James F., School of Earth \& Space Exploration, Arizona State University, P.O. Box 871404, Tempe, AZ 85287, JOHNSON, Jeffrey R., Applied Physics Laboratory, Johns Hopkins University, 11100 Johns Hopkins Road, MP3-E169, Laurel, MD 20723, ARVIDSON, Raymond E., Earth \& Planetary Sciences, Washington University in St. Louis, 1 Brookings Drive, Saint Louis, MO 63130, MITTLEFEHLDT, David W., Astromaterials Research Office, NASA, Johnson Space Center, mail code XI3, 2101 NASA Parkway, Houston, TX 77058, RUFF, Steven W., Arizona State University, Tempe, AZ 85287-6305 and RICE, Melissa S., Geology Department, Western Washington University, 516 High St, Bellingham, WA 98225, farrand@spacescience.org

Since early 2015, the Mars Exploration Rover Opportunity has been exploring the break in the rim of Endeavour Crater dubbed Marathon Valley by the rover team. Marathon Valley was identified by orbital hyperspectral data from the MRO CRISM as having a relatively strong spectral feature in the $2.3 \mu \mathrm{m}$ region indicative of an $\mathrm{Mg}$ or $\mathrm{Fe}-\mathrm{OH}$ combination overtone absorption band indicative of smectite clay. Earlier in its mission, Opportunity examined the Matijevic Hill region on the more northerly Cape York crater rim segment and found evidence for smectite clays in a stratigraphically lower, pre-impact formed unit dubbed the Matijevic formation. However, the smectite exposures in Marathon Valley appear to be associated with the stratigraphically higher Shoemaker formation impact breccia. Evidence for alteration in this unit in Marathon Valley is provided by Pancam multispectral observations in the 430 to $1010 \mathrm{~nm}$ visible/near infrared (VNIR) spectral range. Sinuous troughs ("red zones") contain fragmented cobbles and pebbles displaying higher blue-to-red slopes, moderately higher $535 \mathrm{~nm}$ band depths, elevated 754 to $934 \mathrm{~nm}$, and negative 934 to 1009 $\mathrm{nm}$ slopes. The lack of an absorption at 864 to $904 \mathrm{~nm}$ indicates the lack of crystalline red hematite in these red zones, but likely an enrichment in nanophase ferric oxides. The negative 934 to $1009 \mathrm{~nm}$ slope is potentially indicative of the presence of adsorbed or structurally bound water. A scuff in a red zone near the southern wall of Marathon Valley uncovered light-toned soils and a pebble with an 803 to $864 \mathrm{~nm}$ absorption resembling that of light-toned Fe-sulfate bearing soils uncovered by the Spirit rover in the Columbia Hills of Gusev crater. APXS chemical measurements indicated enrichments of $\mathrm{Mg}$ and $\mathrm{S}$ in the scuff soils and the pebble, Joseph Field, with the strongest $803 \mathrm{~nm}$ band- consistent with $\mathrm{Mg}$ and Fe sulfates. The presence of $\mathrm{Fe}$ and $\mathrm{Mg}$ sulfates can be interpreted as evidence of a potentially later episode of aqueous alteration with an earlier, neutral to alkaline $\mathrm{pH}$ episode forming the Fe/Mg smectites and a later acid $\mathrm{pH}$ episode forming the $\mathrm{Fe}$ and $\mathrm{Mg}$ sulfates. 


\begin{abstract}
ID\#: 283381
Password: 390489

Meeting: GSA Annual Meeting in Denver, Colorado, USA - 2016

Session Type: Topical Sessions

Primary Selection: T167. Mineral Spectroscopy-Harnessing Energy to Probe Solid Bodies in the Solar System: The G.K. Gilbert Award Session

Final Session Number:

Abstract Title: MULTISPECTRAL VNIR OBSERVATIONS BY THE OPPORTUNITY ROVER PANCAM OF MULTIPLE EPISODES OF AQUEOUS ALTERATION IN MARATHON VALLEY, ENDEAVOUR CRATER, MARS

Preferred Presentation Format: Oral

Discipline Categories: Planetary Geology
\end{abstract}

\title{
Abstract Submission Fee: \\ Presenting Author \\ William H. Farrand \\ Space Science Institute \\ 4750 Walnut Street \\ \#205 \\ Boulder, CO 80301
}

Phone Number: 720-974-5825

Email: farrand@spacescience.org

Student? N

James F. Bell III

Arizona State University

P.O. Box 871404

School of Earth \& Space Exploration

Tempe, AZ 85287

Phone Number: (480) 965-1044

Email: Jim.Bell@asu.edu

Student? N

Jeffrey R. Johnson

Johns Hopkins University

11100 Johns Hopkins Road

MP3-E169

Applied Physics Laboratory

Laurel, MD 20723

Phone Number: 240-228-1609

Email: Jeffrey.R.Johnson@jhuapl.edu

Student? N

Raymond E. Arvidson

Washington University in St. Louis

1 Brookings Drive

Earth \& Planetary Sciences

Saint Louis, MO 63130

Phone Number: (314) 935-5609 
Fax Number: (314) 391-6259

Email: arvidson@wunder.wustl.edu

David W. Mittlefehldt

Johnson Space Center

mail code XI3

2101 NASA Parkway

Astromaterials Research Office, NASA

Houston, TX 77058

Phone Number: 281-483-5043

Email: david.w.mittlefehldt@nasa.gov

Student? N

Steven W. Ruff

Arizona State University

Tempe, AZ 85287-6305

Phone Number: 480-965-6089

Fax Number: 480-965-1787

Email: steve.ruff@asu.edu

Student? N

Melissa S. Rice

Western Washington University

516 High St

Geology Department

Bellingham, WA 98225

Phone Number: 626-840-2521

Email: melissa.rice@wwu.edu

Student? N 